\title{
Acceptability, Waste and Nutritional Adequacy of Primary School Canteen Menus: An Observational Study in Pavia, Northern Italy
}

Giovanna Turconi*, Lidia Testa, Stefania Moro, Miriam Rossi, Carla Roggi and Laura Maccarini

Department of Public Health, Experimental and Forensic Medicine-Unit of Human Nutrition and Dietetics, Faculty of Medicine, University of Pavia, Italy

\begin{abstract}
The aim of the study was to determine the acceptability, waste and nutritional adequacy of lunches served in all public primary school canteens in Pavia, Northern Italy.

School canteens of all public primary schools were investigated to determine the acceptability, waste and nutritional adequacy of their menus. In addiction, the environment of the canteens (brightness, noisiness, size, crowding, cleanliness, attractiveness) was observed. The observations were conducted from April to June 2012. In each school canteen, lunch was supervised for three consecutive days by 5 trained dietitians.

In total, 13 schools, 22 classes and 448 schoolchildren aged 7-8.5 years were investigated. The school canteens were found to be hygienically appropriate and homely. The menus offered appeared nutritionally adequate but portion sizes were often too big for the children's age. Consequently a lot of waste was encountered, especially fruit and vegetables ( $70 \%$ of children refused vegetables), but first and main courses were also wasted ( $50 \%$ of children consumed a first course and the same proportion consumed a main course).

The meals offered by the school canteens appeared nutritionally appropriate although portion-sizes were often too large for 7-8.5 aged schoolchildren. The quality and variety of the menus were good and the raw materials were usually D.O.P. (Protected Denomination of Origin) as a guarantee of high quality. This study has drawn attention to the need to adapt the menus to the children's age in order to reduce waste.
\end{abstract}

Keywords: Canteen menus, Primary school, Menu acceptability, Menu waste, Menu adequacy

\section{Introduction}

The promotion of a healthy diet during childhood contributes not only to better mental, social and physical health during this life stage, but also sets the basis for better health throughout life course, and contributes to a longer life with better quality [1]. Considering that children's eating is modified by exposure to and accessibility of foods [2], the supply of healthy school meals could play a strategic role in improving children's diet.

The school setting is a crucial part of the social environment that shapes eating behavior, especially given that children's food preferences are learned through repeated exposure to foods $[3,4]$.

School food services are an integral part of the school environment and are an ideal focus for efforts on improving the nutrition of school children [3].

In Italy, school meals are regulated by the National Government [5], which establishes norms and regulations regarding food safety and administrative management of the service, including subcontracting of catering providers and foodservice staff. The National law also regulates the nutritional adequacy of school meals.

Schools are required to serve meals consistent with the Italian Guidelines for School meals issued by the Ministry of Health [5]. These guidelines formalize standards for minimum levels of food energy and nutrients on the basis of the Italian Recommended Dietary Allowances (RDA) [6] for children at different ages. School lunches generally consist of a first course (pasta, rice or soup), a main course (meat, fish, cheese or eggs), vegetables, fruit (or yogurt or fruit juice), bread and mineral water.

Within the national framework, local authorities develop their own Guidelines for school meals, which should be consistent with the national ones. However, despite the Guidelines, there is a high risk for many pupils of not assuming the recommended nutrient intake. This may happen because some pupils often take second helpings of those foods that they most prefer, especially first courses. Therefore, second helpings are consumed as an alternative to other dishes, or sometimes in addition to the whole meal, making the standardized meal unbalanced in terms of either energy or nutrients. Second helpings may be served due to inadequate training of foodservice staff, but could also be due to a real need of a food supplement for some pupils.

On the other hand, some pupils do not appreciate the meals and leave most of the food on the dish.

This plate waste has a negative impact not only on children's health but also in terms of costs. Many studies have suggested that plate waste may occur because of a lack of knowledge of students' preferences and acceptance of menu items, as well as of inadequate temperature and quality of food $[7,8]$.

However, another reason for plate waste can be found in school meal portion sizes, which might be too big and not always suitable for all children.

*Corresponding author: Giovanna Turconi, Department of Public Health, Experimental and Forensic Medicine-Unit of Human Nutrition and Dietetics, Faculty of Medicine, University of Pavia, Italy, Tel: 00390382 987544; Fax: 0039 0382 987570; E-mail: gturconi@unipv.it

Received October 28, 2013; Accepted November 08, 2013; Published November 11, 2013

Citation: Turconi G, Testa L, Moro S, Rossi M, Roggi C, et al. (2013) Acceptability Waste and Nutritional Adequacy of Primary School Canteen Menus: An Observational Study in Pavia, Northern Italy. J Nutr Food Sci 3: 238. doi: 10.4172/2155-9600.1000238

Copyright: (c) 2013 Turconi G, et al. This is an open-access article distributed under the terms of the Creative Commons Attribution License, which permits unrestricted use, distribution, and reproduction in any medium, provided the original author and source are credited. 
School meals also play an important role in the development of the socialization process and a good school canteen environment could turn lunch into a special occasion where pupils can relax, speak to each other, taste new dishes and learn to really appreciate food. Indeed, providing an adequate and attractive school canteen environment is as important as improving the quality and the healthiness of food [9].

The aim of the present study was to evaluate the acceptability, waste and nutritional adequacy of lunches served in all public primary school canteens in Pavia, Northern Italy. A second aim was to investigate the environment of the canteens, including brightness, noisiness, size, crowding, cleanliness and attractiveness.

\section{Methods}

Four hundred and forty eight healthy subjects $(95.3 \%$ of the children attending the second year of all the public primary schools $(\mathrm{n}=13,22$ classrooms in Pavia) participated in the study, 52.5\% males and $47.5 \%$ females, among whom 71 were immigrant children. Twenty two children, 16 Italians and 6 foreigners, refused to participate because their parents were not interested in the project. The mean age of the sample is $7.7 \pm 0.4$ years (range $7-8.5$ ).

This survey was carried out as part of a wider nutritional surveillance project conducted with the cooperation of the Education Department of Pavia City Hall, and also included assessment of anthropometric measurements, investigation of children's and families' dietary habits, children's physical activity level as well as the families' socio-economic status and educational level and parents' BMI.

All children were surveyed over the course of three months, from April to June 2012.

The study was conducted with the cooperation of both the school teachers and the Education Department of Pavia City Hall. Before beginning the study, many meetings were organized together with teachers to explain the aim of the research and to request their participation.

Children's parents were informed of the purpose of the research by letter that was sent together with a consent form through which written informed consent was obtained from them.

This study was conducted according to the guidelines laid down in the Declaration of Helsinki and all procedures involving human subjects were approved by the Ethics Committees of Pavia University Medical School.

\section{Meal observation}

All schools observed were catered for by a catering provider contracted by the local authority (Pavia City Hall). This catering provider distributes thousands of meals every day in all public schools in Pavia.

Meals are prepared using the Cook and Hold and Serve system. Special menus for students with particular dietary needs (for example, gluten-free menus for children with celiac disease, carbohydratecontrolled menus for pupils with diabetes, or other alternative menus for children with food allergies) are cooked separately.

Lunch menus served to schoolchildren are planned by Caterer nutritionists and should be consistent with the 2002 Lombardy Guidelines [10] for School meals based on the Italian Recommended Dietary Allowances [6].

The price of a meal is based on family income and can vary from $€$ 5.00 for a high income family to $€ 0.50$ for a low income family.
Before starting the observation period in each school canteen, the menu available for the days in question was requested from school foodservice managers. The observation took place for three consecutive days for a total of 1126 observations during lunch time, which lasted from 12:30 to 13:30, after an appointment with the school teachers. Five trained dietitians visually estimated the children's food consumption. The dietitians had received 3 hours of instruction and had been standardized in the observation assessment. Intra- and inter-operator variability was assessed on a subsample of 20 children and was $<3 \%$ for all the observations.

Before starting lunch in the canteen, the dietitian assessed the menu available for that day with the canteen staff. A label with name, surname and class was given to each child in order to recognize the pupils. A teacher for each class consumed her/his meal together with the pupils.

For each serving, consumption was estimated using a four-point scale (all, half, none, second helping) and data were recorded on a standardized sheet.

In the case of non-consumption, the child was asked about it by the dietitian and usually answered: "I don't like it" or "Mom cooks it better" or "I like it, but I'm not hungry" or "It's too cold".

The menu served consisted of a first course, a main course, vegetables, fruit or dessert, bread and mineral water. The first and main courses were sometimes replaced by a single dish, such as pizza or polenta with fish or meat.

The observation lasted for the duration of lunch time. The dietitians were also asked to evaluate the canteen environment: brightness, noisiness, size, crowding, cleanliness and attractiveness were estimated using a rating scale and data were recorded on a standardized form.

\section{Nutritional composition of the canteen menus}

School foodservice managers were asked to provide a description of all the school menus (meal, ingredients, recipe description, weight and portion size) offered during the observation period. Two dietitians computed the energy and nutritional content (kilojoules, protein, total fat, saturated fatty acids, carbohydrates, sugar and dietary fiber) of 11 randomly selected menus using a web-based nutritional program containing the food composition tables of the European Institute of Oncology database [11]. A comparison was then made between our menu calculations and the national and regional guidelines $[5,10]$.

\section{Statistical analysis}

All statistical analyses were performed using SPSS statistical software package for Windows Version 18.0 (SPSS Inc., Chicago, IL, USA, 2010).

Descriptive statistics (means and standard deviations) and frequency distribution were calculated.

\section{Results}

\section{Lunch observation}

During the observation period, out of 448 children, only 415 pupils had lunch in the school canteen; of these, 32 had only one lunch, 55 had two lunches and 328 had three lunches. Over the three days, the total number of observations was 1126 (586 observations of boys and 540 observations of girls).

The most common reasons why some children did not have lunch in school canteen were absence from school (absence due to illness or for a medical examination) or the practice of having lunch at school only a few days per week. 
Citation: Turconi G, Testa L, Moro S, Rossi M, Roggi C, et al. (2013) Acceptability, Waste and Nutritional Adequacy of Primary School Canteen Menus: An Observational Study in Pavia, Northern Italy. J Nutr Food Sci 3: 238. doi: 10.4172/2155-9600.1000238

Page 3 of 6

On the whole, school meals were served in about half an hour and the lunch break lasted an hour for all pupils observed.

Figure 1 shows the percentage of first courses, main courses, vegetables and dessert helpings consumed by children (boys and girls) during the 3-day observation period.

A comparison between first course and main course consumption shows that most of the children liked the first course more than the main course.

Indeed, about half $(49.6 \%)$ of the first course helpings served during the observation period were consumed by the children (only $18.4 \%$ were almost entirely left in the plate), but only slightly more than a third of the main course helpings served were eaten completely, whereas most $(40.8 \%)$ were left over. Over two thirds of the vegetable helpings served were left uneaten.

As shown in Figure 1, children's favourite dish was dessert: more than half of portions of dessert were completely consumed and only a third of helpings were left over.

\section{Food items consumed during lunches}

Food variety was adequate and raw materials were usually D.O.P. (Denomination of Origin Protected) as guarantee of high quality. D.O.P. was set up in 1992 by the European Community (Reg. CEE 2081/92) and offers warranty during the whole food production: origin, source and local dietary traditions.

Table 1 shows the food groups more and less consumed in school canteens during the three days observation period. Children usually preferred first courses, and above all liked pasta, risotto (over $50 \%$ of helpings consumed) and vegetable soups.

Less than $50 \%$ of the main course helpings served was consumed by the children. However, it is worth noting that, among main courses, the most consumed was cheese, whereas the most uneaten was savory pies and fish.

Observing the vegetable consumption, Table 1 shows that children generally did not like vegetables. Indeed the percentages of vegetable helpings left on the plate by children exceeded $50 \%$ for both cooked and raw vegetables, even if, the most unpalatable were cooked vegetables.

Regarding desserts, ice cream and yogurt, as expected, were the most consumed but a good percentage of fruit was consumed too.

Finally, as far as bread consumption is concerned, about $53 \%$ of bread helpings served was left over while approximately $22 \%$ of portions were completely eaten.

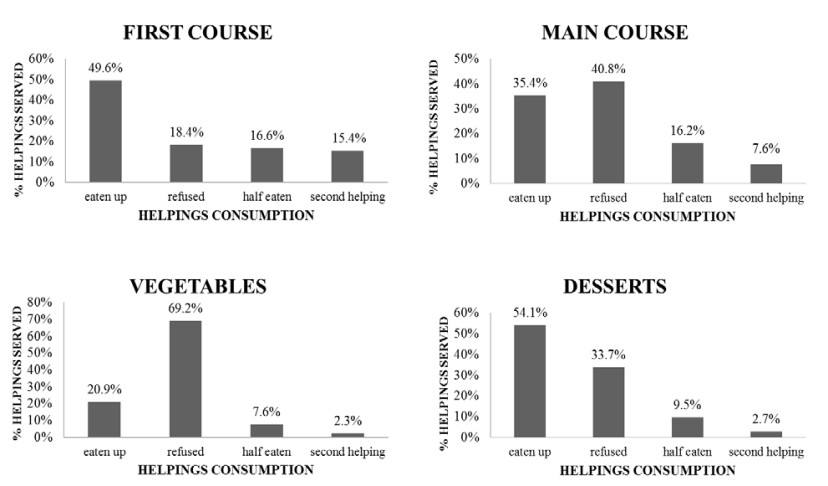

Figure 1: Servings consumption during the observation period $(n=1126)$.
Figures 2-5 show the various types of dishes most consumed by children during the observation period.

For each course (first courses, main courses, vegetables and desserts) the four most accepted recipes are indicated and for each recipe the percentages of helpings eaten up, left over, half-eaten and second helpings are shown. Among desserts special attention is given to fresh fruit.

Children generally liked simple dishes: as shown in Figure 2, among first courses, the most appreciated recipes were "Pasta with herbs", "Pasta with ragout", "Pasta with extra virgin olive oil and parmesan", and "Vegetable soup with croutons".

Cheese was the leading type of main course consumed and seasoned cheeses and soft cheeses were the favorites. The most popular meat was stuffed meat and omelet with ham was the most consumed.

Children generally disliked all kinds of vegetables, especially cooked vegetables, whereas the raw vegetables such as salads and tomatoes were wasted less.

Among cooked vegetables, potatoes and mashed potatoes were the least wasted, while among desserts, as far as fruit consumption is concerned, bananas were the most consumed fruit item followed by fruit mousse, oranges and apples.

\section{Special menus}

Special menus were cooked for $5.3 \%$ of the students. Nine percent of special menus were gluten-free, $4.5 \%$ were carbohydrate-controlled

\begin{tabular}{|l|c|c|c|}
\hline COURSES & FOOD PRODUCTS & $\begin{array}{c}\text { HELPINGS } \\
\text { CONSUMED \% }\end{array}$ & $\begin{array}{c}\text { HELPINGS } \\
\text { LEFT OVER \% }\end{array}$ \\
\hline \multirow{3}{*}{ FIRST COURSES } & Pasta & 55.9 & 15.4 \\
\cline { 2 - 4 } & Risotto & 51.9 & 17.6 \\
\cline { 2 - 4 } & Vegetable soups & 46.1 & 28.0 \\
\hline \multirow{4}{*}{ MAIN COURSES } & Cheese & 44.0 & 22.9 \\
\cline { 2 - 4 } & Meat & 36.5 & 40.7 \\
\cline { 2 - 4 } & Omelet & 34.3 & 39.4 \\
\cline { 2 - 4 } & Savory Pies & 32.3 & 50.6 \\
\cline { 2 - 4 } & Fish & 29.1 & 48.6 \\
\hline \multirow{3}{*}{ DESSERTS } & Cooked vegetables & 16.4 & 74.0 \\
\cline { 2 - 4 } & Raw vegetables & 23.3 & 67.3 \\
\cline { 2 - 4 } & Ice cream & 83.9 & 3.2 \\
\cline { 2 - 4 } & Yogurt & 70.4 & 20.0 \\
\cline { 2 - 4 } & Fruit mousse & 57.6 & 37.0 \\
\hline \multirow{2}{*}{ BREAD } & Fresh fruit & 50.6 & 36.3 \\
\hline
\end{tabular}

Table 1: Food products consumed during lunches by children.
PASTA WITH HERBS

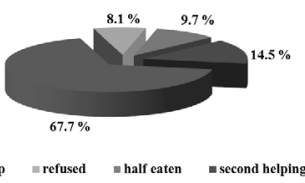

PASTA WITH EXTRAVIRGIN OLIVE OIL AND PARMESAN

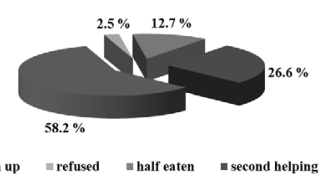

PASTA WITH RAGOU'

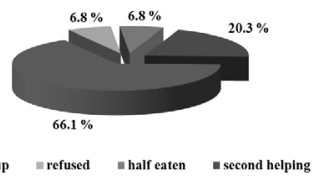

VEGETABLE SOUP WITH CROUTONS

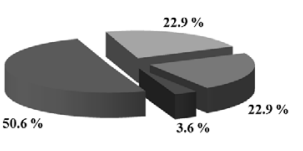

Figure 2: First courses most consumed during the observation period. 
Citation: Turconi G, Testa L, Moro S, Rossi M, Roggi C, et al. (2013) Acceptability, Waste and Nutritional Adequacy of Primary School Canteen Menus: An Observational Study in Pavia, Northern Italy. J Nutr Food Sci 3: 238. doi: 10.4172/2155-9600.1000238

Page 4 of 6

menus for pupils with type I diabetes, $32.0 \%$ were menus suitable for Muslim children and $54.5 \%$ were menus for children with food allergies or intolerances.

\section{Nutritional composition of the canteen menus}

As far as the nutritional adequacy of school meals concerns, Tab. 2 shows a comparison of the energy and nutritional content of 11 randomly selected menus with the regional (Lombardy) [10] and Italian Guidelines [5] for School meals (children aged between 6-11 years). All the values are in line with the Italian RDA [6] (Table 2).

\section{Portion weights}

As shown in Table 3, the portion weight of first courses served to pupils (excluding vegetables soups and broth) was $75 \mathrm{~g}$ on average. This portion weight is similar to the Italian recommended portion size for an adult [6] (80 g) and therefore exceeds the recommended serving size for children.

As for main courses, it can be noted that the weight of a helping of meat (130 g on average) exceeds even the recommended portion size for an adult, while the portion weight for fish ( $100 \mathrm{~g}$ on average) is that recommended for an adult (Figures 3 and 4).

As far as vegetables and fruits are concerned, portion sizes were generally consistent with those recommended for children.

\section{Discussion}

The findings obtained in the present study could be used to improve the local school meal system.

School meals play an important role in children's diet; lunches typically contribute between one-quarter to one-third of children's daily

\begin{tabular}{|c|c|c|c|}
\hline & $\begin{array}{c}\text { Lombardy } \\
\text { Guidelines (2002) }\end{array}$ & $\begin{array}{l}\text { Italian Guidelines } \\
\text { (Ministry of Health, } \\
\text { 2010) }\end{array}$ & $\begin{array}{l}\text { Our Results } \\
\text { Mean SD }\end{array}$ \\
\hline $\begin{array}{l}\text { Energy } \\
(\mathbf{k J}, \%) \S\end{array}$ & $\begin{array}{l}3213 \\
40 \%\end{array}$ & $\begin{array}{c}2176-3389 \\
35 \%\end{array}$ & $3322 \pm 381$ \\
\hline $\begin{array}{l}\text { Proteins } \\
(\mathbf{g}, \%)^{*}\end{array}$ & $\begin{array}{c}28 \\
15 \%\end{array}$ & $\begin{array}{l}13-30 \\
10-15 \%\end{array}$ & $\begin{array}{c}36.0 \pm \\
18.2 \pm 3.3 \\
\pm\end{array}$ \\
\hline $\begin{array}{c}\text { Fats } \\
(\mathrm{g}, \%)^{*}\end{array}$ & $\begin{array}{c}26 \\
30 \%\end{array}$ & $\begin{array}{c}18-27 \mathrm{~g} \\
30 \%\end{array}$ & $\begin{array}{l}22.2 \pm 5.4 \\
25.1 \pm .6 \%\end{array}$ \\
\hline $\begin{array}{l}\text { Saturated Fats } \\
(\mathrm{g}, \%)^{\star}\end{array}$ & $\begin{array}{c}8 \\
10 \%\end{array}$ & $\begin{array}{c}6-9 \\
10 \%\end{array}$ & $\begin{array}{c}5.9 \pm 1.8 \\
6.6 \pm 1.9 \%\end{array}$ \\
\hline $\begin{array}{c}\text { Carbohydrate } \\
(\mathrm{g}, \%)^{*}\end{array}$ & $\begin{array}{r}106 \\
55 \%\end{array}$ & $\begin{array}{r}106 \\
55 \%\end{array}$ & $\begin{array}{l}119.9 \pm 16.6 \\
56.7 \pm 6.0 \%\end{array}$ \\
\hline $\begin{array}{c}\text { Simple sugars } \\
(\mathbf{g}, \%)^{*}\end{array}$ & $\begin{array}{c}31 \\
16 \%\end{array}$ & $\begin{array}{c}13-30 \\
10-15 \%\end{array}$ & $\begin{array}{c}25.5 \pm 5.3 \\
12.0 \pm 2.1 \%\end{array}$ \\
\hline
\end{tabular}

§lunch meal percentage from total daily energy intake

*percentage from meal energy content

Table 2: Comparison of Our Results with the Regional (Lombardy) and Italian Guidelines for School meals for children aged between 6 and 11 years. intake of energy and nutrients [12,13]. Having lunch at school gives children the opportunity to taste new foods, but, above all, offers the basis for healthy eating in adulthood.

Our findings indicate that, although the schools provide lunches that almost completely meet the 2002 Lombardy Guidelines for School meals [10], there are three concerns about school lunches, often associated with children's inadequate intake of energy and nutrients: plate waste, portion sizes and second helpings.

In addition to the food discarded and the consequent high associated costs, plate waste may reduce benefits that pupils can receive from a nutritionally balanced school lunch. Healthful eating and regular physical activity help in optimizing physical and cognitive development, maintaining healthful weight and reducing the risk of some chronic diseases [14].

Although we did not weigh foods at the beginning and end of the meal, visual estimation of the children's food consumption allowed us to highlight that more than half of the food served was discarded.

Plate waste is influenced by the type and appearance of meals provided, appetite and taste $[7,8]$. As our results show, children seemed to consume first courses more than main courses. This could be attributed to children's preference for them, but it could also be associated with

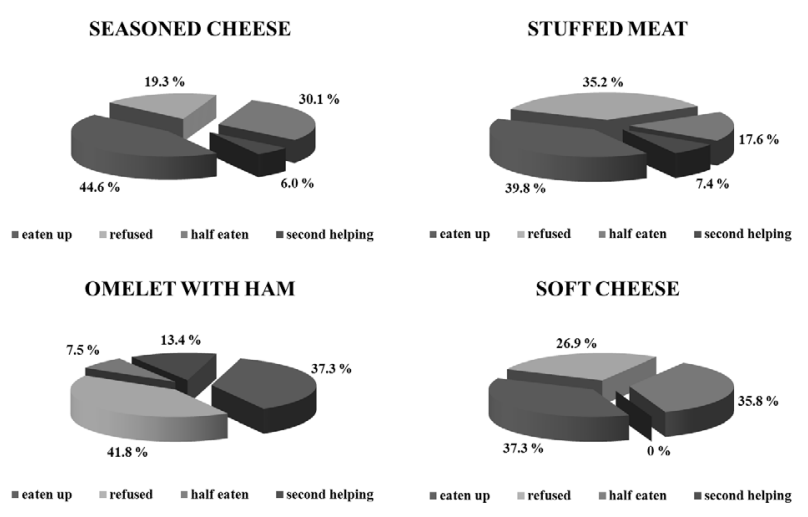

Figure 3: Main courses most consumed during the observation period.
COOKEDVEGETABLES

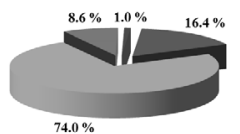

RAW VEGETABLES

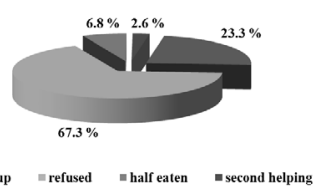

Figure 4: Vegetables acceptance during the observation period.

\begin{tabular}{|c|c|c|c|c|c|c|c|c|c|c|c|c|c|}
\hline MENUS & 1 & 2 & 3 & 4 & 5 & 6 & 7 & 8 & 9 & 10 & 11 & Mean S & \\
\hline $\begin{array}{l}\text { First course } \\
\text { (g) }\end{array}$ & 80 & 25 & 80 & 70 & 40 & 80 & 70 & 70 & 25 & 70 & 80 & $\begin{array}{c}62.7 \\
* 75.0\end{array}$ & $\begin{array}{l}21.8 \\
5.3\end{array}$ \\
\hline $\begin{array}{l}\text { Main course } \\
\text { (g) }\end{array}$ & 90 & 100 & 65 & 130 & 130 & 40 & 100 & 130 & 100 & 60 & 90 & $\begin{array}{l}94.1 \\
\S 108.7\end{array}$ & $\begin{array}{l}29.9 \\
18.1\end{array}$ \\
\hline Vegetables (g) & 170 & 120 & 85 & 150 & 80 & 50 & 90 & 150 & 90 & 150 & 120 & 114.1 & 37.9 \\
\hline $\begin{array}{l}\text { Fruit and desserts } \\
\text { (g) }\end{array}$ & 125 & 150 & 150 & 150 & 150 & 150 & 125 & 150 & 45 & 100 & 150 & $\begin{array}{l}131.4 \\
\circ 150.0\end{array}$ & $\begin{array}{l}33.1 \\
0\end{array}$ \\
\hline
\end{tabular}

${ }^{\circ}$ mean value of fresh fruit

Table 3: Portion weights $(\mathrm{g})$ for different foods from 11 randomly selected menus offered in school canteens.

* mean value excluding vegetables soups and broth

$\S$ mean value of meats and fishes 


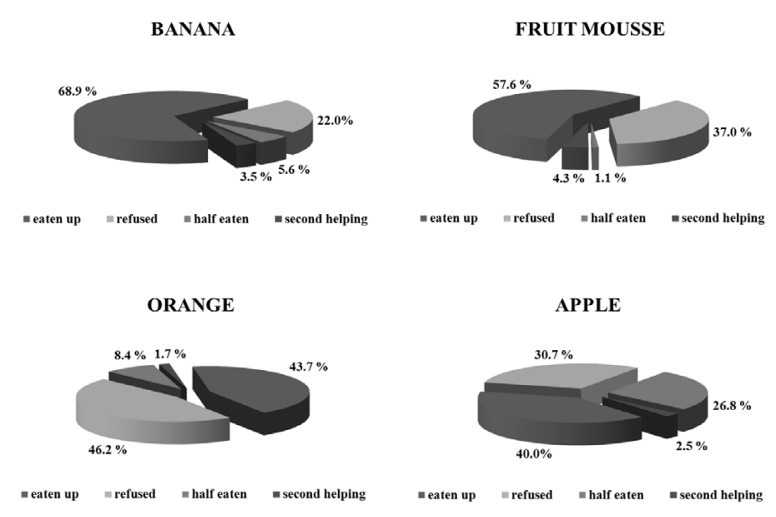

Figure 5: Fruit most consumed during the observation period.

another reason. Schoolchildren are usually hungry at lunchtime; so it is clear that they eat more and more quickly at the beginning of the lunch. This results not only in a rather high consumption of the first course helping, but also in a widespread demand for second helpings: indeed, for first courses the percentage of second helpings served was about $20 \%$.

After finishing the first course, however, children are almost full up, both because of the portion size of the first course, quite large for a child, as already pointed out, and because most of them ate a second helping. As a result, schoolchildren generally discarded a high quantity of the main course and bread and are likely to have an unbalanced meal.

Tailored training for serving staff should be required in agreement with other studies $[15,16]$ in order to reduce food waste and ensure that children eat a truly balanced meal. Serving staff should be trained to refuse second helpings, to give the same portion size to all school children and, lastly, portion sizes tailored more closely to children's real needs.

In particular, special attention must be given to portion sizes of first courses, meat and bread: regarding bread, for instance, the portion size currently offered which is too big for children of this age, could be replaced by small bread rolls and buns that are popular among children [17].

Children's low consumption of vegetables is consistent with data from international studies [18-21] even though vegetable and fruit deserve a separate mention.

The percentage of vegetables discarded was as much as $70 \%$, while fresh fruit discarded was about $36 \%$.

Children generally dislike vegetables for many reasons, such as their texture, fibrous and hard to eat, or their taste that is often strong and bitter [22-25]. Indeed, we found that the most discarded vegetable dish was "ratatouille" (85.5\%), a stewed mix of onions, eggplant, peppers, tomatoes and zucchini, while salads were the most consumed vegetable dish, together with potatoes and mashed potatoes which were wasted less, in agreement with the findings of other studies [26,27].

School foodservice managers and dietetics professionals should support children's preferences and include vegetables with characteristics most likely to be accepted by children (i.e. bland taste, crunchy texture etc.) more often in school lunch menus, while avoiding the more frequently discarded vegetables (e.g. chicory and chards) or trying to make them more palatable (e.g. adding them to vegetable soups and vegetable dishes that children like).
Vegetables that children usually discard, especially leafy greens and cruciferous vegetables like broccoli, are rich in antioxidant vitamins and minerals useful for good health status: since vegetables are an acquired taste and repeated taste exposure has been reliably shown to be associated with increased liking and consumption [18,28], pupils' families should also be encouraged to offer vegetables that their children dislike at home.

As for fresh fruit, we found that the most popular fruit was ripe, quick and easy to eat. Fruit mousse was appreciated for its creamy texture and sweet taste, but at the same time fresh fruit like bananas or oranges were also liked by schoolchildren.

As far as fruit consumption is concerned, it has been suggested that sliced fruit is more likely to be consumed than whole portions [29]. Thus, in order to increase children's fruit acceptance, the school lunch caterer should provide fruit presented in small pieces, colorful, juicy and ripe, already peeled or easy to peel [18].

Adding fresh fruit salads and just-squeezed fruit juices to school lunch menus could be a helpful suggestion.

The environment in which food is consumed plays an important role in acceptability, choice and consumption [17,30]. Both physical characteristics (e.g. space, color, noise or light of the eating environment) and context (e.g. food quality, décor) are important $[17,30]$. A pleasant atmosphere in the dining area is an important component of the school lunch. Indeed, an enjoyable dining space can promote social skills and provide the opportunity to sit and eat with friends [31].

Several experiments conducted in school canteens in order to observe a child's eating behavior in primary and secondary schools found that after making even small improvements to the environment of dining spaces, children discarded 38\% less food on average [9].

We found that the school canteens were clean and bright, but they were not colorful and engaging for children. We noticed, for example, a lack of drawings or posters related to nutrition and food, which could provide pupils with nutritional information, and the absence of pictures with nice healthy dishes that could encourage children to eat them.

School is an important setting for children to learn about and practice healthy dietary habits $[32,33]$. Teachers, therefore, have a fundamental role because they can explain the importance of balanced nutrition during school lessons; school should also promote extracurricular activities with the participation of nutrition experts and involve families and children in nutrition educational projects.

Finally, schools, food and nutrition professionals, families and children should work together to develop a high quality school lunch menu consistent with nutrition standards but also appealing to children: this could be the right way to reduce food waste, save money and, above all, offer children a healthy, balanced and tasty diet.

The present study has a few limitations that must be considered. First, to determine school food consumption and waste, we did not weigh foods at the beginning and end of a meal, but estimated children's food intake by direct observation. Research where foods are weighed provides more accurate and detailed information, but, as other studies demonstrate, it is expensive and time-consuming [14,34,35].

Direct observation of food intake by visual estimation during school meal time is an unobtrusive method to evaluate children's food consumption and has been used to validate other intake assessment systems [36-39]. However, observers, even if trained, may have different 
Citation: Turconi G, Testa L, Moro S, Rossi M, Roggi C, et al. (2013) Acceptability, Waste and Nutritional Adequacy of Primary School Canteen Menus: An Observational Study in Pavia, Northern Italy. J Nutr Food Sci 3: 238. doi: 10.4172/2155-9600.1000238

abilities in estimating the amount of food consumed and discarded and this could be source of bias.

Another limitation may be highlighted: the trained observers did not taste the foods offered to school children and this would have been useful to better understand the reasons for food being discarded (e.g. inadequate temperature, undercooked foods, etc.).

Despite these limitations, this study also shows some strength. The length of the observation period (three months in total, three consecutive days in each school, and 1126 observations) allowed us to evaluate a wide variety of school lunch menus and their different levels of acceptability among schoolchildren. In addition, we examined school lunch time as a whole, having analyzed not only the meal, but also the environment of the dining areas.

In conclusion, the findings obtained in this study highlight some critical points of the school meal system operating in public primary schools in Pavia and allowed us to identify the strategies that could improve the efficiency of the school lunch system itself.

\section{Acknowledgements}

The authors would like to express their acknowledgement to the staff of the Education Department of Pavia City Hall: Dr. R. Faldini, Dr. M. Adduci, Dr. P. Mangiarotti, Dr. F. Gallone, Dr. F. Biffi, Dr. L. La Carbonara. They are very grateful to all the teachers, the pupils and their parents for their continuous cooperation and to the dietitians for the meal observation assessment.

The research was supported by grants from Pavia City Hall Education Department.

\section{References}

1. Dixey R, Heindl I, Loureiro I, Perez-Rodrigo C, Snel J et al. (1999) Healthy eating for young people in Europe. A school-based nutrition education guide. International Planning Committee (IPC). Copenhagen: WHO.

2. Birch LL, Fisher JO (1998) Development of eating behaviors among children and adolescents. Pediatrics 101: 539-549.

3. Drummond C, Sheppard L (2011) Examining primary and secondary schoo canteens and their place within the school system: a South Australian study. Health Educ Res 26: 739-749.

4. Golan M, Crow S (2004) Parents are key players in the prevention and treatment of weight-related problems. Nutr Rev 62: 39-50.

5. Ministero della Salute, Dipartimento per la sanità pubblica veterinaria, la nutrizione e la sicurezza degli alimenti, Direzione generale della sicurezza degli alimenti e della nutrizione (2010) Linee di indirizzo nazionale per la ristorazione scolastica.

6. SINU Società Italiana di Nutrizione Umana (1996) LARN - Livelli di Assunzione di Riferimento di Nutrienti ed energia per la popolazione italiana, revisione 1996

7. Marlette MA, Templeton SB, Panemangalore M (2005) Food type, food preparation, and competitive food purchases impact school lunch plate waste by sixth-grade students. J Am Diet Assoc 105: 1779-1782.

8. Jansen GR, Harper JM (1978) Consumption and plate waste of menu items served in the National School Lunch Program. J Am Diet Assoc 73: 395-400.

9. The importance of better eating environments.

10. Regione Lombardia, Direzione Generale Sanità, Unità Organizzativa Prevenzione (2002) Linee Guida della Regione Lombardia per la ristorazione scolastica.

11. Salvini S, Parpinel M, Gnagnarella P, Maisonneuve P, Turrini A (2008) Banca dati di composizione degli alimenti per studi epidemiologici in Italia. Milan: Istituto Europeo di Oncologia.

12. School Food Trust (2009) Primary School Food Survey 2009.

13. Cross M, MacDonald B (2009) Nutrition in Institutions. Wiley-Blackwell, Oxford, UK.

14. Buzby JC, Guthrie JF (2002) Plate waste in school nutrition programs: final report to Congress. Economic Research Service, USDA.
15. Howell Davies O, Suleiman S, Nicholas J, Bradbury J, Msebele S, et al. (2008) Food portion weights in primary and secondary school lunches in England. $J$ Hum Nutr Diet 21: 46-62.

16. Casey $L$ (2003) The validity of portion size estimates in primary school children BSc Nutrition. London: King's College London.

17. van Woudenbergh NM (2005) Boys' views on school meals: Food preferences, consumption patterns and recommendations.

18. Hendy HM, Williams KE, Camise TS (2005) "Kids Choice" school lunch program increases children's fruit and vegetable acceptance. Appetite 45: 250-263.

19. Gleason P, Suitor C (2000) Changes in children's diets: 1989-91 to 1994-96. Washington, DC: United States Department of Agriculture, Food and Nutrition Service.

20. Heimendinger J, Van Duyn MA (1995) Dietary behavior change: the challenge of recasting the role of fruit and vegetables in the American diet. Am J Clin Nutr 61: 1397S-1401S.

21. Guenther PM, Dodd KW, Reedy J, Krebs-Smith SM (2006) Most Americans eat much less than recommended amounts of fruits and vegetables. J Am Diet Assoc 106: 1371-1379.

22. Drewnowski A, Mennella JA, Johnson SL, Bellisle F (2012) Sweetness and food preference. J Nutr 142: 1142S-8S.

23. Mennella JA, Pepino MY, Reed DR (2005) Genetic and environmental determinants of bitter perception and sweet preferences. Pediatrics 115: e216-222.

24. Mennella JA, Pepino MY, Duke FF, Reed DR (2010) Age modifies the genotypephenotype relationship for the bitter receptor TAS2R38. BMC Genet 11: 60 .

25. Olsho LE, Fernandes MM (2013) Relationship of white potato to other vegetable consumption by schoolchildren and adolescents in the USA: National Health and Nutrition Examination Survey, 2003-2008. Public Health Nutr 16: 1933-1936.

26. Lee HS, Lee KE, Shanklin CW (2001) Elementary students' food consumption at lunch does not meet recommended dietary allowance for energy, iron, and vitamin A. J Am Diet Assoc 101: 1060-1063.

27. Coldwell SE, Oswald TK, Reed DR (2009) A marker of growth differs between adolescents with high vs. low sugar preference. Physiol Behav 96: 574-580.

28. Lakkakula A, Geaghan J, Zanovec M, Pierce S, Tuuri G (2010) Repeated taste exposure increases liking for vegetables by low-income elementary school children. Appetite 55: 226-231.

29. Upton D, Upton P, Taylor C (2012) Fruit and vegetable intake of primary schoo children: a study of school meals. J Hum Nutr Diet 25: 557-562.

30. Meiselman HL, Johnson JL, Reeve W, Crouch JE (2000) Demonstrations of the influence of the eating environment on food acceptance. Appetite 35: 231-237.

31. Department of Education, Northern Ireland (DENI), corp creator. (2010) Improving the dining experience in schools.

32. Wood L, Harper C (2008) The link between child nutrition and health: an overview of research in the UK

33. School Meals Review Panel (2005) Turning the tables: transforming school food.

34. Cohen JF, Richardson S, Austin SB, Economos CD, Rimm EB (2013) Schoo lunch waste among middle school students: nutrients consumed and costs. Am J Prev Med 44: 114-121.

35. Gray C, Lytle LA, Perry C, Story M, Taylor G, et al. (2007) Fruits and vegetables taken can serve as a proxy measure for amounts eaten in a school lunch. J Am Diet Assoc 107: 1019-1023.

36. Shankar AV, Gittelsohn J, Stallings R, West KP Jr, Gnywali T, et al. (2001) Comparison of visual estimates of children's portion sizes under both sharedplate and individual-plate conditions. J Am Diet Assoc 101: 47-52.

37. Domel SB, Baranowski T, Leonard SB, Davis H, Riley P, et al. (1994) Accuracy of fourth- and fifth-grade students' food records compared with school-lunch observations. Am J Clin Nutr 59: 218S-220S

38. Simons-Morton BG, Forthofer R, Huang IW, Baranowski T, Reed DB, et al. (1992) Reliability of direct observation of schoolchildren's consumption of bag lunches. J Am Diet Assoc 92: 219-221.

39. Mertz W (1992) Food intake measurements: is there a "gold standard"? J Am Diet Assoc 92: 1463-1465. 